\title{
Liquid metal embrittlement mechanism*
}

\author{
ZHOU Guohui (周国辉), LIU Xiaomin (刘晓倿), WAN Farong (万发荣), \\ QLAO Lijie（乔利杰）、CHi Wuyang（褚武扬）, \\ (Department of Materials Physics, University of Science $\iota$ nd T trawiogy Beijing, Beijing 100083, China) \\ ZHAING 泟encing (张文清), CHEN Nanxian (陈难先) \\ (Instivite of Applied Physıcs, University of Science and Technology Beijing, Beijing 100083, China) \\ and ZHOU Fuxin (周富信) \\ (Institute of Mechanics, Chinese Academy of Sciences, Beijing 100080, China)
}

Recelved October 5, 1998

\begin{abstract}
Liquid metal embrittlement was studied in the following two aspects. First the first principle and ChenNanxian three-dimensional lattice reverse method were employed to obtain the effective potentials for Al-Ga and GaGa. Then with the molecular dynamics simulation, the influence of liquid metal adsorption on dislocation emission was studied. The simulated result shows that after $\mathrm{Ga}$ atoms are adsorbed on the crack plane in $\mathrm{Al}$ crystal, the critical stress intensity factor decreases, which changes from $0.5 \mathrm{MPam}^{1 / 2}$ (without adsorption) to $0.4 \mathrm{MPam}^{1 / 2}$ (with adsorption). The reason for the reduction in the critical intensity stress factor is that $\mathrm{Ga}$ adsorption reduces the surface energy of the crack plane. Moreover, $7075 \mathrm{Al}$ alloy adsorbing liquid metal $(\mathrm{Hg}+3 \mathrm{~atm} \% \mathrm{Ga})$ was in-situ studied in TEM by using a special constant deflection device. The expermental result showed that liquid metal adsorption could facilitate emission, multiplication and motion of dislocations. When this process reached a critical condition, the brittle microcrack was initiated and propagated from the crack tip or in a dislocation free zone.
\end{abstract}

Keywords: molecular dynamics, stress intensity factor, Ga, liquid metal embrittlement, TEM, 7075 Al alloy.

Currently there are a lot of different viewpoints on the mechanism of brittle fracture induced by liquid metals ${ }^{[1-4]}$. It is generally understood that adsorption decreases surface energy (or bond strength), then causes materials to fail ${ }^{[2-4]}$. We once made some experiments on 7075 aluminum alloy. The results showed that the critical stress intensity factor for crack nucleation was $K_{\mathrm{IC}}(\mathrm{L})=1.7$ $\mathrm{MPam}^{1 / 2}$. This value is one order of magnitude lower than the fracture toughness $K_{\mathrm{IC}}=43$ $\mathrm{MPam}^{1 / 2}$ of 7075 aluminum alloy. Substituting the $K_{\mathrm{IC}}$ value into Orowan's equation $K_{\mathrm{IC}}{ }^{2}=2 \gamma_{\text {eff }}$ $\cdot E /\left(1-\nu^{2}\right)$, the effective surface energy $2 \gamma_{\text {eff }}$ was calculated to be $2 \gamma_{\text {eff }}=37 \mathrm{~J} / \mathrm{m}^{2}$. But the calculated value is also one order of magnitude greater than the real surface energy $\gamma=1.15 \mathrm{~J} / \mathrm{m}^{2}$ of aluminum. Hence, the plastic work $\gamma_{\mathrm{p}}$ is the main item of the resistance to fracture $R=2 \gamma_{\text {eff }}=$ $2 \gamma+\gamma_{p}$ in the process of metal fracture. That is to say, there is localized plastic deformation in brittle failure induced by the adsorption of the liquid metals. Previously Lynch proposed that liquid metals adsorbed on the crack surface, just like hydrogen, will decrease surface energy and enhance localized plastic deformation, then result in brittle fracture ${ }^{[5]}$. The viewpoint, however, has not been tested directly by experiments.

By in-situ TEM observations, Su and his co-workers' result showed that liquid metals

* Project supported by the National Natural Science Foundation of China (Grant Nos. 59725104, 19891180, and $59671042)$. 
adsorbed on the crack surface in Al crystal could facilitate dislocation emission, multiplication and motion. When dislocation emission and motion reaches a critical condition, brittle microcracks nucleate $^{[6]}$. It is important to study liquid metal induced dislocation emission and motion by using molecular dynamics simulation and TEM direct observation.

$\mathrm{Up}$ to now, the potential for $\mathrm{Hg}$ is not available. We developed an inversion met: $\mathrm{t}^{\mathrm{t}} \mathrm{d}$ to obtain the potentials for $\mathrm{Al}-\mathrm{Ga}$ and $\mathrm{Ga}-\mathrm{Ga}^{[7]}$. Moreover, because the sensitivity of tritile sracture of $\mathrm{Al}$ induced by $\mathrm{Ga}$ is quite high, the system $\mathrm{Al}-\mathrm{Ga}$ is used in this calculatior..

It is a new method that liquid mstal embritlement is stua'in fiom the point of view of dislocations. The most dirct approach for itrestigating uislocation emission, multiplication and motion is in-situ TEM terision. Fere a special TEM loading device was designed to study dislocation configuration ahead of a crack tip induced by various media, such as chemical solution and liquid metals ${ }^{[8,9]}$. Our macroscopic experiments showed that 7075 alloy fractured under low stress in liquid metal $\mathrm{Ga}^{[5]}$. The bulk specimen adsorbing $\mathrm{Hg}$ cracked intergranularly. In this paper, by in-situ TEM observation, 7075 alloy was used to study the influence of liquid metal adsorption on dislocation emission, multiplication and motion.

\section{Experimental procedures}

The material used in this investigation was 7075 (LC4) Al alloy. The specimens were kept at $475^{\circ} \mathrm{C}$ for $1 \mathrm{~h}$, followed by water quenching, and then tempered at $135^{\circ} \mathrm{C}$ for $15 \mathrm{~h} .0 .02 \mathrm{~mm}$ thick foil specimens were cut by a spark machine from the bulk material. First the sheets were ground by emery paper to about $100 \mu \mathrm{m}$ in thickness. Then the specimens were thinned by double jet electropolishing in the solution of $10 \% \mathrm{HClO}_{4}+90 \% \mathrm{CH}_{3} \mathrm{CH}_{2} \mathrm{OH}$ until small holes were formed. After these processes, ion bombardment was used to clean the surface and remove hydrogen induced by electropolishing.

The foil specimens were mounted on the special constant deflection device ${ }^{[8,9]}$. A stress was applied with a screw until cracks appeared around the holes and the specimens were put in a desiccator for 20-24 h. After the dislocation configuration ahead of the crack tip was examined, the specimen was crept in TEM for $0.5-1 \mathrm{~h}$. If the dislocation configuration did not change with time any more, it indicated that the creep reached a stable status at room temperature.

The pre-crept specimen with the loading set was put above liquid surface of $\mathrm{Hg}+3 \mathrm{~atm} \% \mathrm{Ga}$ in a closed container. After the adsorption lasted for a given time, we put the foil specimen in TEM, and observed changes of the dislocation configuration ahead of the crack tip and the initiation of microcracks.

\section{Experimental results}

Specimen 1 was loaded by the constant deflection device until dislocations were emitted from the crack tip. Its displacement was kept constant and it was pre-crept in a desiccator for $24 \mathrm{~h}$, then observed in TEM continuously. The dislocation configuration ahead of the crack tip did not change. This indicated that the dislocation configuration reached a stable state, as shown in fig. 1(a). Putting the loading set with the specimen above liquid metal of $\mathrm{Hg}+3 \mathrm{~atm} \% \mathrm{Ga}$ for $30 \mathrm{~min}$ and $1 \mathrm{~h}$, respectively, no change in the dislocation configuration was found by TEM observation, as shown in fig. 1(b). This indicated that careful experimental operation and short time adsorption did not cause any dislocation emission and motion. After the specimen was put above liquid 
metal for about $6 \mathrm{~h}$, the dislocation configuration changed dramatically, as shown in fig. 1(c). Comparing fig. 1(c) with fig. 1(b), we can see that the dislocation density in region CDEF increased obviously, and a new set of dislocations was formed in a region $\mathrm{BC}$. Because the dislocations in the region $\mathrm{BC}$ were laid ahead of the crack tip, they must be emitted from the crack tip A. The increment in dislocation density in the region CDEF originated from dislocations newly emitted from the crack tip or multiplication of the dislocation source. This showed that adsorption of liquid metal, under low loading, can facilitate dislocation emission.

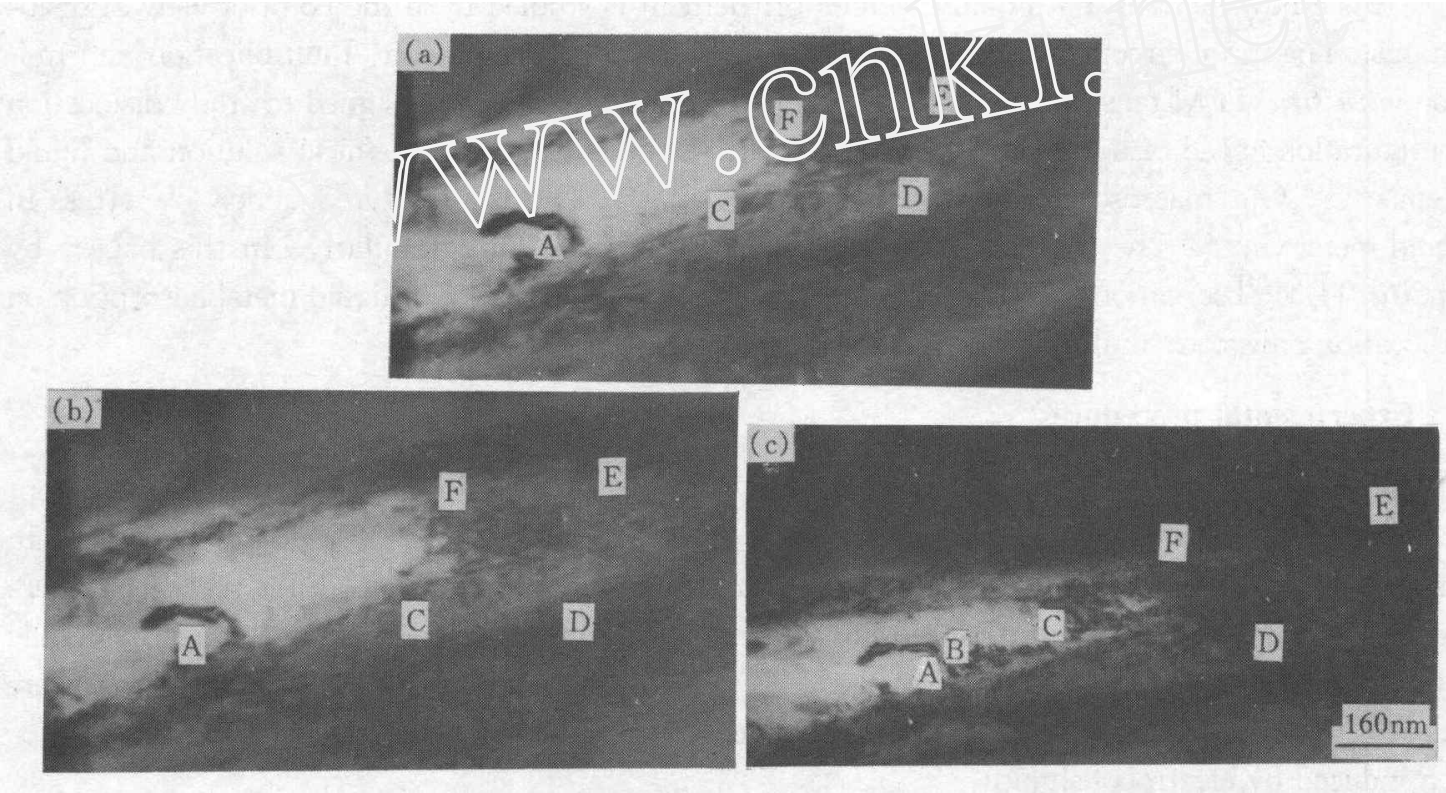

Fig. 1. Effect of metal adsorption on emission and multiplication of dislocations. (a) Original dislocation status in front of a pre-loaded crack tip after $24 \mathrm{~h}$ creeping in air; (b) $1 \mathrm{~h}$ in $\mathrm{Hg}+3 \% \mathrm{Ga}$ atmosphere; (c) $6 \mathrm{~h}$ in $\mathrm{Hg}+3 \% \mathrm{Ga}$ atmosphere.

Specimen 2 was pre-crept for $22 \mathrm{~h}$, then crept in TEM for $0.5 \mathrm{~h}$. The dislocation configuration before the crack tip was shown in fig. 2(a). Putting the specimen above liquid metal for $6 \mathrm{~h}$, we observed that dislocations in the region DE had moved beyond the view field, and meanwhile dislocations in the region BC moved, as shown in fig. 2(b). Specimen 3 was pre-crept for $20 \mathrm{~h}$, then crept in TEM for $0.5 \mathrm{~h}$ until the dislocation configuration reached a stable state, as shown in fig. 3(a). Putting it above liquid metal for $5 \mathrm{~h}$, dislocation configuration changed, as shown in fig. 3(b). Many new dislocations were formed in $\mathrm{BC}$ ahead of the crack tip A. Continuously
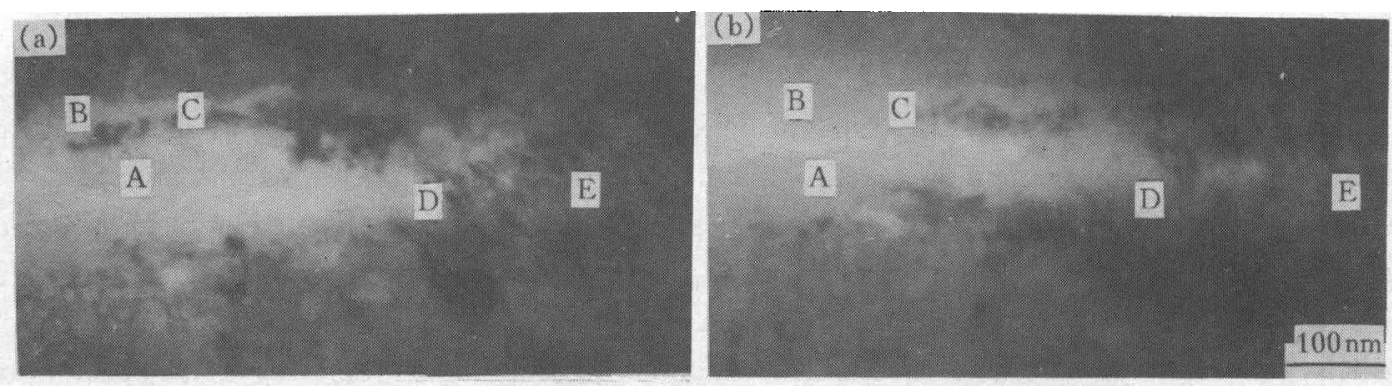

Fig. 2. Enhancement of metal adsorption on dislocation movement. (a) A status pre-crept $22 \mathrm{~h}$; (b) $6 \mathrm{~h}$ in armosphere of the liquid $\mathrm{Hg}+3 \% \mathrm{Ga}$. 
putting it above liquid metal for $2 \mathrm{~h}$, dislocations were emitted, multiplied and moved. Moreover, a DFZ indicated by BCD was formed ahead of the crack tip, but microcracks were not initiated yet, as shown in fig. 3(c). This means that liquid metal adsorption in the crack tip can enhance dislocation emission, multiplication and motion. Previous study showed that the adsorption of $\mathrm{Ga}$ on the crack surface in pure $\mathrm{Al}$ (loading sprcimens were put above liquid of $\mathrm{Ga}$ at $50 \mathrm{C}$ ) cold also facilitate dislocation $\mathrm{errission}$. nultiplication and motion.

\section{Theoretical calculation}

3.1 Procedure of molecular dynamics simulation

The interactive pair potential between $\mathrm{Al}$ and $\mathrm{H}$ can be obtained from $a b$ initio calculation and the Chen-Mobius 3D lattice inversion formula. Then the interactive pair potential was used to investigate the influence of $\mathrm{H}$ on dislocation emission in $\mathrm{Al}$ crystal ${ }^{[7]}$. Similarly, the interaction potentials for $\mathrm{Al}-\mathrm{Ga}$ and $\mathrm{Ga}-\mathrm{Ga}$ can be calculated. The parameters in the Rose's equation of state, i. e. bulk module $B$, equilibrium energy $E_{0}$ and lattice constant $a_{0}$ can be figured out from the first principle calculation. Values of $B$, $E_{0}$ and $a_{0}$ are listed in table 1 . The pair potentials for $\mathrm{Ga}$ and $\mathrm{Al}-\mathrm{Ga}$ are illustrated in fig. 4 . The $\mathrm{N}$-body potential for $\mathrm{Al}$ was used ${ }^{[10]}$.

In FCC crystals, a full dislocation moves on the $\{111\}$ plane in the $\langle 110\rangle$ direction. In the present model, the paper plane was set to be $(1 \overline{2})$ plane, which was used as the projected plane. The purpose is to observe easily the emit-
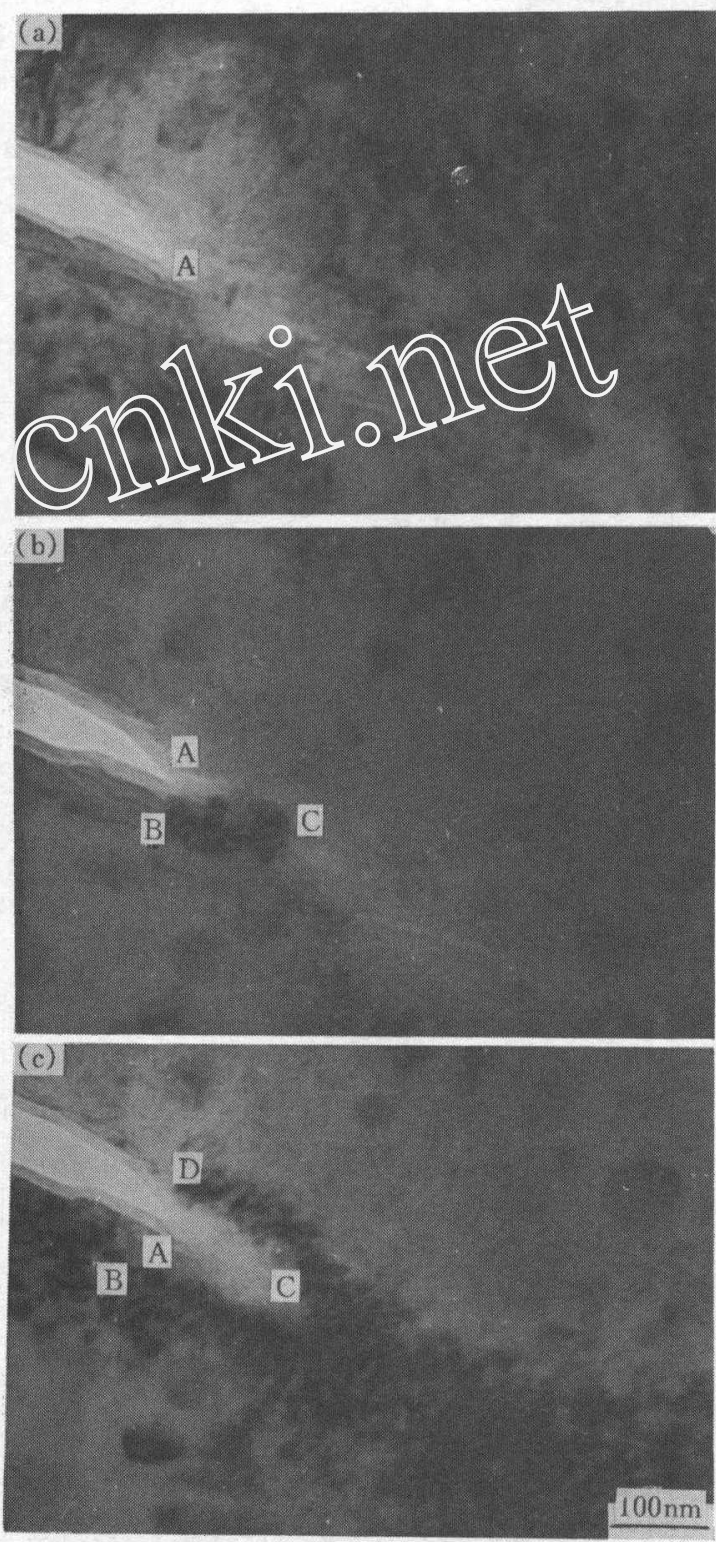

Fig. 3. Enhancement of metal adsorption on dislocation emission, multiplication and movement. (a) An original status pre-crept in air for $20 \mathrm{~h}$; (b) $5 \mathrm{~h}$ in atmosphere of the liquid $\mathrm{Hg}+3 \% \mathrm{Ga}$; (c) $7 \mathrm{~h}$ in atmosphere of the liquid $\mathrm{Hg}+3 \% \mathrm{Ga}$. ted Schockley dislocations. The inclination angle of the slip plane with respect to the crack plane is set to be $70^{\circ} . x, y, z$ axes are along [13 59 , $[19 \overline{35} \overline{8}]$ and $[11 \overline{2}]$, respectively. The length in $x$-direction is $35 a_{0}$, in $y$-direction $40 a_{0}$ and in $z$-direction $\frac{\sqrt{6}}{12} a_{0}$ (one period). The total atom number is 6640 . The loading direction is in $y$ direction, so the crack is mode I. The boundary conditions applied to the boundary of the discrete atom region in the simulation are dictated by a mode I anisotropic $\mathrm{K}$ field in the $x-y$ plane. In the $z$-direction, a six-layer periodic representation is applied. The time step is $\Delta t=0.005 \mathrm{ps}$. The 
temperature of the model is set to be $100 \mathrm{~K}$. Calculation details are similar to those in reference [7].

Table 1 Values of $B, E_{0}$ and $a_{0}$ calculated from the first principle

\begin{tabular}{lccc}
\hline & $B \times 10^{11} \mathrm{~N} \cdot \mathrm{m}^{-2}$ & $E_{0} \times 1.60 \times 10^{-9} / \mathrm{J}$ & $a_{0} \times 10^{-10} / \mathrm{m}$ \\
\hline $\mathrm{Al}$ & 0.742 & 3.835 & 4.101 \\
$\mathrm{Ge}$ & 0.805 & 3.220 & 4.169 \\
$\mathrm{AlGa}$ & 0.686 & 3.149 & 3.235 \\
\hline
\end{tabular}

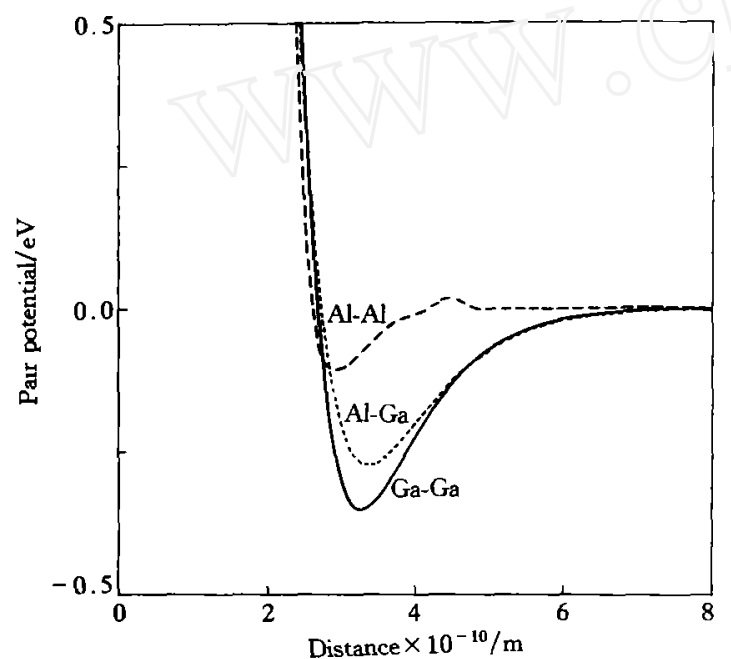

Fig. 4. Pair potentials of $\mathrm{Ga}$ and $\mathrm{Ga}-\mathrm{Al}$.

\subsection{Simulated results and discussion}

For pure Al crystal, when the applied stress intensity factor is $K_{\mathrm{I}}=0.5 \mathrm{MPam}^{1 / 2}$, the first partial dislocation was emitted. It moved in the plane (111) (see fig. 5(a)). It means that the critical stress intensity factor of the crack in mode $\mathrm{I}$ in $\mathrm{Al}$ crystal was $K_{\mathrm{Ie}}=0.5 \mathrm{MPam}^{1 / 2}$. If $\mathrm{Ga}$ atoms are adsorbed on the crack plane, only when the stress intensity factor is $K_{\mathrm{I}}=0.4 \mathrm{MPam}^{1 / 2}$, a partial dislocation will be emitted from the crack tip, as shown in fig. 5(b). That is to say, if Ga atoms are adsorbed on the crack plane, the critical stress intensity factor will reduce from $K_{\mathrm{I}}=0.5$ $\mathrm{MPam}^{1 / 2}$ to $K_{\mathrm{I}}=0.4 \mathrm{MPam}^{1 / 2}$, which decreases by $20 \%$. When load was applied further, the partial dislocations emanated from the crack tip unceasingly. At the same time, a step "abcdef" appeared ahead of the crack tip, as shown in fig. 6(a). Adsorbed $\mathrm{Ga}$ atoms can change the atomic configuration ahead of the crack tip. A vacancy cluster was produced, as indicated by "A" in fig. 6 (b). Because there exist super-saturated vacancies, one Frank dislocation $(b=[111] / 3)$ was produced near the crack tip, as indicated by "B" in fig. 6(b). Schockley dislocations will also be emitted from the crack tip.

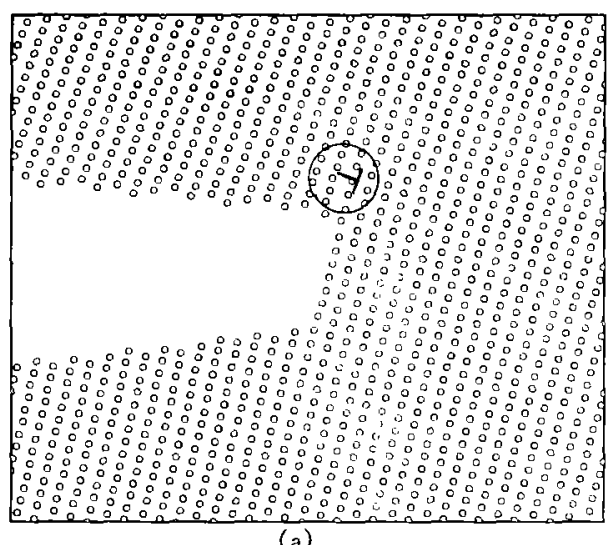

(a)

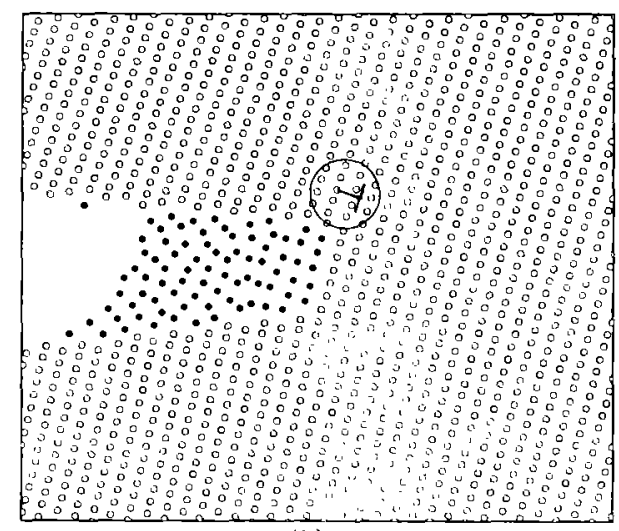

(b)

Fig. 5. Effect of $\mathrm{Ga}$ adsorption on critical stress intensity factor for dislocation emission. (a) First emitted dislocation at $0.5 \mathrm{MPam}^{1 / 2}$ without $\mathrm{Ga}$ adsorption; (b) first emitted dislocation at $0.5 \mathrm{MPam}^{1 / 2}$ with $\mathrm{Ga}$ adsorption. 

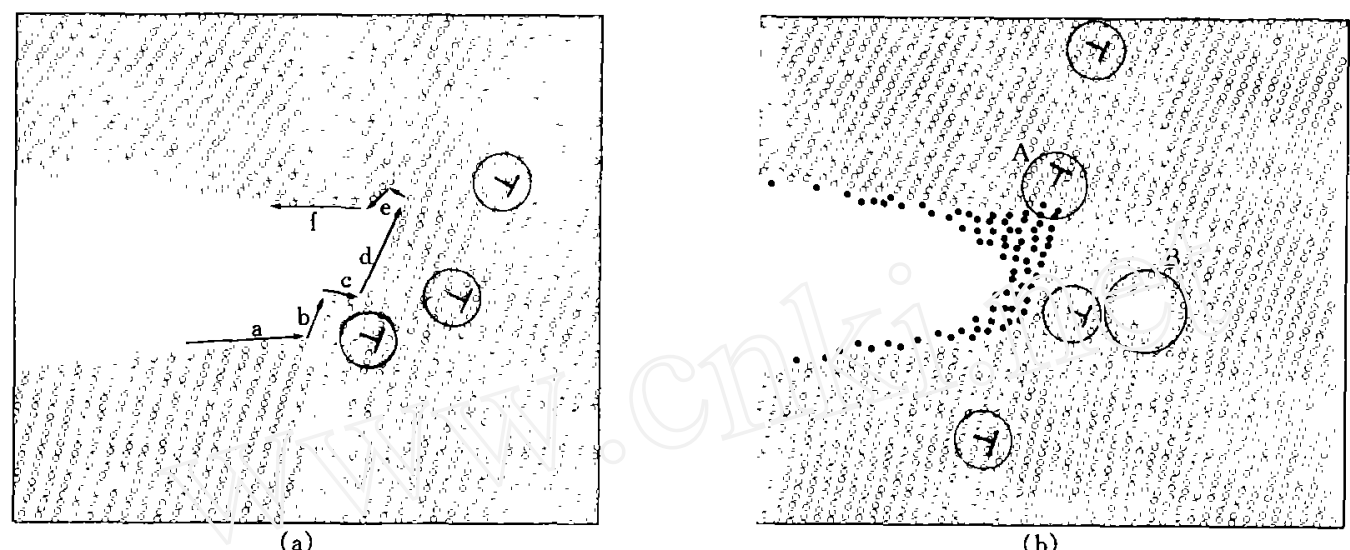

(b)

Fig. 6. Effect of $\mathrm{Ga}$ adsorption on configuration of $\mathrm{Al}$ atoms around the crack tip. (a) $K_{\mathrm{I}}=1.1 \mathrm{MPam}^{1 / 2}$ without $\mathrm{Ga}$ adsorption; (b) $K_{\mathrm{I}}=1.1 \mathrm{MPam}^{1 / 2}$ with Ga adsorption.

The reason that absorbed metal atoms can reduce the critical stress intensity for dislocation emission is related to surface energy. The critical stress intensity factor for dislocation emission under mode I crack can be expressed as ${ }^{[11]}$

$$
K_{\mathrm{le}}=\frac{2}{\sin \phi \cos \left(\frac{1}{2} \phi\right)}\left\{\frac{\mu b}{(1-\nu)\left(8 \pi r_{\mathrm{c}}\right)^{1 / 2}}+\left(2 \pi r_{\mathrm{c}}\right)^{1 / 2}\left[\sigma_{\mathrm{f}}+\frac{4 \gamma \mathrm{e}^{1 / 2} \sin \phi}{\pi r_{\mathrm{c}}\left(1+\mathrm{e}^{3}\right)}\right]\right\},
$$

where $\phi$ is an angle between the crack plane and the dislocation slip plane, $\mu$ the shear modulus, $b$ Burgers' vector, $\nu$ Poison ratio, $r_{\mathrm{c}}$ the radius of a dislocation core, $\gamma$ the surface energy and $\sigma_{\mathrm{f}}$ lattice resistant, which is $\mathrm{P}-\mathrm{N}$ force for a perfect crystal. For $\mathrm{Al}$ crystal, the values of the parameters are $r_{\mathrm{c}}=d / c$, and the angle $\phi$ is $70^{\circ}, b=1.65 \times 10^{-10} \mathrm{~m}, \mu=26.3 \mathrm{GPa}, \nu=0.34, \sigma_{\mathrm{f}}=$ $10^{-5} \mu . \sigma_{\mathrm{f}}$ is small enough to be neglected. Substituting all the data into eq. (1), $K_{\mathrm{Ie}}$ is calculated to be $0.38 \mathrm{MPam}^{1 / 2}$. There is relationship between $\mu$ and $\gamma^{[12]}$ :

$$
\gamma=\frac{E a^{2}}{\pi^{2} d}=\frac{2 \mu(1+\nu) a^{2}}{\pi^{2} d},
$$

where $a$ is the lattice constant, $d=\frac{\sqrt{6}}{3} a_{0}$ is the effective distance of crystal plane. The data for $\mathrm{Hg}$ is used as a sample here. $\mathrm{Hg}$ adsorption will decrease surface energy for $\mathrm{Al}$ from $\gamma=1.15 \mathrm{~J} / \mathrm{m}^{2}$ to $\gamma=0.35 \mathrm{~J} / \mathrm{m}^{2[4]}$. From eq. (2) we get $\mu(\mathrm{L})=\mu \gamma^{\prime}(\mathrm{L}) / \gamma=0.304 \mu=8.0 \mathrm{GPa}$. Substituting the value of $\mu_{\mathrm{L}}$ into eq. (1), $K_{\mathrm{Ie}(\mathrm{L})}$ is calculated to be $0.114 \mathrm{MPam}^{1 / 2}$. Because of lack of surface energy for $\mathrm{Al}$ with $\mathrm{Hg}$ adsorption, we cannot carry on quantitative calculations.

\section{Conclusion}

1) The adsorption of liquid metal on the crack plane in 7075 aluminum alloy can facilitate dislocation emission, multiplication and motion.

2) The molecular dynamics simulation showed that $\mathrm{Ga}$ adsorption on $\mathrm{Al}$ crack plane decreased the critical stress intensity from $0.5 \mathrm{MPam}^{1 / 2}$ to $0.4 \mathrm{MPam}^{1 / 2}$, and liquid metal adsorption would facilitate dislocation emission. 


\section{References}

1 Nicholas, M. G., Old, C. F., Liquid metal embrittlement, J. Mater. Sci., 1979, 14: 1.

2 Kelley, M. J., Stoloff, N. S., Analysis of liquid metal embrittlement from a bond energy viewpoint, Met. Trans. , 1975, 6A: 159.

3 Lynch, S. P. , Overview of evidence for an adsorption-induced localized-ilip process, Acte Metall. , 1988, $36: 2639$.

4 Kargol, J. A. , Albrighy, D. L. , The effect of relative crystal crientatic- on the lquid nietal induced grain boundary fracture of aluminum bicrystals, Metall. Trans., 1977, 8A: 77.

5 Liu Xiaomin, Qiao Lijie, Chu Wuyang, The liquid netal ent rittlement of sluininum, Acta Metall. Sinica, 1998, $34: 2$.

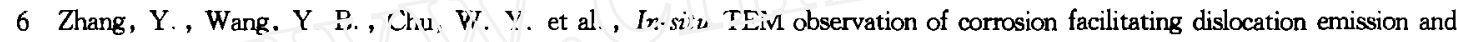
motior for uriss. Scribta Mutall., 192:5, 32: 637.

7 Zhou Guotix:, 2hou Fusin, Thu Wuyang et al. , The molecular dynamics simulation of hydrogen enhancing dislocation emission, Science in China (in Chinese), Ser. E, 1998, 28: 1.

8 Gu Biao, Zhang Jingwu, Wang Farong et al. , The $\imath n$-situ TEM observation of corrosion-facilitating dislocation emission motion for brass, Scripta Mater. , 1995, 32: 637.

9 Gao Kewei, Wang Yanbin, Chu Wuyang, In-situ TEM observation of dissolution enhanced dislocation emission, motion and the nucleation of SCC for Ti-24Al-11Nb alloy in methanol, Scripta Mater. , 1997, 36: 259.

10 Yan, M., Vitek, V., Chen, S. P., Many-body central force potentials and properties of grain boundaries in NiAl, Acta Metall. , 1996, 44(11): 4351 .

11 Ohr, S. M. , An electron microscope study of crack tip deformation and its impact on the dislocation theory of fracture, Mater. Sci. Eng., 1985, 72: 1.

12 Cherepanov, G. P. , Mechanics of Brittle Fracture, New York: McGraw-Hall Inter Book Comp. , 1974, 29. 